\title{
A Narrative Study on Jennifer Egan's Early Fiction
}

\author{
Baoyu Nie \\ School of Foreign Studies \\ Henan Agricultural University \\ Zhengzhou, China 450002
}

\begin{abstract}
The Invisible Circus, Jennifer Egan's first novel published in 1995, has started her novel-writing career. It focuses on an eighteen-year-old girl Phoebe who has always been haunted by the mysterious death of her hippie older sister and was attracted by the 1960s generation, searching for her own identity. Egan's second fiction, Look at Me, focuses on the stories of two "Charlottes" who are searching for their true selves. This paper explores the narrative strategies in Egan's early fictions, and points out that by mainly employing internal focalization, Egan's first fiction reflects the influence the 1960s counterculture had brought to the protagonists; in Look at Me, Egan adopts alternative narratives to tell the stories of characters. In the process of first-person narrative, Egan uses unreliable first-person narrative to tell the story of the protagonist. This paper concludes that Egan's early fictions deal with issues around the image culture, examining the role of media representation in the 1960 s counterculture as well as demonstrating eloquently how often fiction, in its visionary form, speaks of truth.
\end{abstract}

Keywords-Jennifer Egan; The Invisible Circus; Look at Me; narrative; image culture

\section{INTRODUCTION}

Jennifer Egan, winner of the 2010 National Book Critics Circle Award, the 2011 Pulitzer Prize and other forty literary awards for the fiction A Visit From the Goon Squad (2010), is a contemporary American fiction writer with popular appeal and a novelist of ideas noted for the elegance of her style. Her writing defies fixed characterization, with each fiction taking on new structures, characters, moods and narrative strategies. Egan utilizes narratives including not only traditional narratives but also postmodern ones, especially new media narratives in her fiction. However, despite the diversity of playing with literary techniques, the central concerns of Egan's fiction remain constant. Fascinated by the American obsession with image, she ties her narratives to the profound exploration on the real culture. Image culture and its ramifications absorb her and connect with other interests, such as self-invention or reinvention, losses and regrets as people change with time, personal redemption, the exploration of the role of technology in our lives and so on.

By mainly employing internal focalization to reflect Phoebe's elder sister Faith who represents the 1960s

This paper is supported by Henan Science and Technology Department Project "Research on the College English Cultural Teaching of Henan Province" Project No. 162400410280; Henan Agricultural University Youth Project "Traditional' Postmodern Narrative-Research on Jennifer Egan's Works" Project No. KJCX2015B06. generation, The Invisible Circus begins to look at some of the issues around the image culture and to examine the role of media representation in the 1960 s counterculture. It also probes into the question of how to create "identity" from outside, which sees ourselves as images to affect who we really are. In Look at Me, Egan adopts alternative narratives between first-person narrative and third-person narrative to tell the stories of characters. In the process of first-person narrative, Egan uses unreliable first-person narrative to tell the story of the protagonist. This fiction deals with the issues around image culture in depth. It demonstrates eloquently how often fiction, in its visionary form, speaks of truth.

\section{A BRIEF REVIEW OF THE EARLY FICTIONS}

Inspired and encouraged by the success of her short stories, Egan decided to revise the so called "failed novel" she had begun while studying at Cambridge University. Originally titled "Inland Soul", a phrase from the first line of Emily Dickinson's poem "Exultation is Going": "Exultation is going of an inland soul to sea...", The Invisible Circus mainly portrays the post-Boomer generation's nostalgia for the 1960s they just missed out. Opening in 1978, it concerns an eighteen-year-old girl Phoebe O'Connor, who has always been haunted by the mysterious death of her hippie teenage sister Faith in Italy seven years ago. Newly graduated from high school, Phoebe is restless at home in San Francisco after discovering her widowed mother is romantically involved with her boss. She is further horrified when her mother insists that her father, a would-be painter whose day job was being an IBM executive, had no talent in art at all but only "invented that myth to comfort himself". (IC, 92) With the help of precious postcards from Faith that she has preserved for years, Phoebe leaves San Francisco for Europe, determined to retrace her sister's journey and find out the truth of her sister's suicide.

On her way to Europe, Phoebe visits London, Amsterdam, France, and Germany and finds the burned-out remnants of the once vibrant counterculture world of the 1960s. In Amsterdam, she is cheated and trapped and even almost raped by some disguised drug dealers who claim to know her sister Faith. In Paris, she even takes a trip in the classic Sixties sense, taking a hit of LSD (lysergic acid diethylamide) in a scene that climaxes in throwing herself at a glass window, behind which she thinks she sees her sister Faith. In Berlin, she meets with Wolf, her sister's old boyfriend and they travel together to Italy to the place where her sister has jumped off the cliff. 
Together with Wolf, Phoebe succeeds in uncovering the motives of her sister's suicide and in the process finds her own meaning of life and claims her own identity. Along the way, we learn about Phoebe's family in the days before her father's death from cancer and Faith's presumed suicide. The father, a frustrated painter and an IBM executive, encourages Faith's reckless behavior again and again as a way of making up for "all kinds of myths about himself". (IC, 95) It becomes clear that after the father's death, Faith turns more or less mad and even participates in some revolutionary movement and murders an innocent man by bombing a building. Disturbed and tortured by self accusation, Faith eventually chooses to commit suicide by falling from a cliff. When Phoebe is finally able to locate and visit the cliff, she has a better understanding of her sister and the 1960s generation. She is "riven, then, by a vision of her sister unlike any she'd had before: a girl like herself, reaching desperately for something she couldn't see but sensed was there, a thing that always seemed to evade her." (IC, 317) It seems that Phoebe has found her own identity and has discovered something larger than Faith's death. To read the fiction is actually to see the Sixties again in all its glimmering and illusive promise. The story in The Invisible Circus goes to the ambiguous heart of the people who were living in the 1960s: they tried to follow the dreams of freedom, only to find that the ideals had been disintegrated.

The title of her first fiction "The Invisible Circus" comes from a real event of a theatrical group called the "Diggers" who were active in San Francisco in the late 1960's, which has a strong influence on the book's characters Wolf and Faith. ${ }^{1}$ The title also refers to the reverberations from the Sixties felt as inner turmoil in younger brothers and sisters who were not quite old enough to be there, just as the protagonist Phoebe. The success of The Invisible Circus appealed to Hollywood, and it was adapted into a film by starring a young Cameron Diaz as Faith, Jordana Brewster as Phoebe, Blythe Danner as the girls' mother, and Christopher Eccleston as Faith's boyfriend Wolf and the movie was released in 2001.

Like Phoebe in The Invisible Circus, Egan spent some time backpacking alone through Europe when she was nineteen-year-old between high school and college period. During the trip she almost had no connection with her family in America, which was an experience that taught her a lot about disconnectedness and surely turned into the basics of her first fiction. The two sisters in The Invisible Circus also have some relationship with her own experience. When she was still a little child and was working at a day camp, she met two twin girls. She was fascinated by them especially by the difference and similarity between twins, a kind of motif that often emerges in her fictions. The fascination and the feeling of longing that many people have for some other self,

\footnotetext{
${ }^{1}$ This information comes from an email I have received from Jennifer Egan. Answering my question of what The Invisible Circus refers to, she wrote: "One thing I can tell you quickly is that "The Invisible Circus" was a real event that took place in San Francisco in the late 1960s. I learned about it from a book called RINGOLEVIO, by Emmett Grogan, who was part of a theatrical group called the 'Diggers' who were active in San Francisco in the late 1960's."
}

that is, the so called "doppelganger" influences her so much on creating the two sisters in The Invisible Circus. She admitted that though there are seven years gap differences between Phoebe and Faith, they look rather alike, "the two sisters ... are essentially twins". (Vida, 78) In the book, Phoebe is so pleased when people tell her that she looks just like her older sister Faith.

Egan paid for her European trip by working as a model for six months which is perhaps the inspiration of her second fiction Look at Me. With her height, five feet nine inches, and the right bone structure, Egan and modeling seem a natural fit. But modeling did not suit her long. She said that she felt "a desire to vanish and to speak - the two things you can't ever do as a model." (Kenny, 73) During her travels in Europe, she was so lonely because she felt there was so little that held her inside. So, she formed the habit of writing what she had observed and what she had thought along the way of her journey. Talking about her European experience, Egan reflects that "writing was an integral part of my experience of the world, and that would always be." (Van Aalst, 32) Returning from Europe, she entered college with a new seriousness of purpose, which accorded with what Phoebe did after her returning from Europe in The Invisible Circus.

Egan earned her Bachelor's Degree in English major at the University of Pennsylvania and Master Degree in English literature at St. John's College in Cambridge University where she met the man who became her husband later, David Herskovits, a theater director. At that time, based upon her year of travel in Europe, she began her first draft of the fiction The Invisible Circus but did not succeed. So she turned to nonfiction writing. Among which her first publication in the New Yorker, "Why China", was based on her traveling in China in $1986^{2}$. Another short story, "The Stylist" was a great success and consequently caught the attention of many literary agents. It evolved out of a story she wrote for a class which she enrolled after graduating from Cambridge. Concerned with image culture, the story holds a sardonic view of the older stylists who are starving for the coveted "cover story", which also has become the rudiment of her second fiction Look at Me.

Published in fall of 2001, a week after the terrorist attacks on the World Trade Center and Pentagon, Egan's interest in the allurement of images led her to scrutinize the fashion industry and the brief and intense careers of top models in her second fiction of her creative process, Look at $M e$. This fiction is different from her previous book in almost every aspect, although the central themes and concerns remain the same. In The Invisible Circus, the setting shifts from America to Europe, in Look at Me, Rockford and Manhattan serve as the two significant places. Whereas the character of Phoebe maintains the central point of view in The Invisible Circus, Egan adopts multiple focalizations in Look at Me. Different from "seeking identity" in The Invisible Circus, there is no search of identity in Look at Me but rather a relinquishment of identity.

\footnotetext{
${ }^{2}$ This information comes from an email I have received from Jennifer Egan Answering my question of her travelling in China, Egan told me that she was in China for two months in July and August of 1986.
} 
In Look at Me, Egan cleverly writes about the conflict between self and image, she realizes that American culture has replaced identity with image: true beauty with the idea of beauty or fashion, paper money has replaced gold coins. "Don't look at yourself through their eyes-don't," one character named Moose pleads, "or they will have won, because ... because we are what we see." (LM, 149) That is, if we become our reflected images, we all but cease to exist.

Egan's message in the fiction is carried by a tale of two Charlottes, one aged thirty five and the other sixteen; one a successful Manhattan fashion model whose face is destroyed and then reconstructed after a car accident, the other a troubled teenager in Illinois seduced by a mysterious and, as it slowly becomes clear, a psychotic stranger who turns out to be a would-be terrorist. Both Charlottes are at their distinct existential cries of first love and individuation and their shared feeling of being not beautiful. The older Charlotte, Charlotte Swenson, in particular, is longing to live her life in her former image of beauty after a serious accident which results in the distortion of her face.

The book begins with a car crash which happens just a few miles outside Rockford, Illinois, the model Charlotte's hometown, that alters her appearance. Though not disfigured, Charlotte's face is so badly shattered that it takes eighty titanium screws to reassemble it. After the accident, she looks more or less normal, but no longer anything like her old self. She is oddly recognizable to the fashionable set that has populated her world. "After the accident," she says in the book's opening lines, "I became less visible." (LM, 3) When she returns to New York she finds that, without her old image, she must begin the search for a new identity. Along the way, she becomes involved in a hunt for a mysterious man named Z, meeting a charming detective and selling her story to an internet service called "Ordinary People," though she herself has been deemed "Extraordinary." Eventually, she finds that she must choose between this newly created image of herself and her true self.

Meanwhile, Charlotte's young namesake, Charlotte Hauser, the teenage daughter of Charlotte Swenson's old school friend Ellen, is also plagued by the way others see her. By frankly embracing and acting her own sexual yearnings, and by failing to present to the world an acceptable appearance, the alienated and disaffected young Charlotte has rendered herself something of a pariah in her high school, Rockford, Illinois. Unlike her girlfriends, young Charlotte has no interest in fashion and artifice. On the one hand, she longs to recreate herself in the socially acceptable image of her friends. On the other hand, she finds herself attracted to the shocking teachings of her wired Uncle Moose and to a mysterious math teacher Michael West who is actually the missing Z

Egan spent six years in composing Look at Me, and it shows that it is a sprawling, ambitious book that links together some of the most diverse characters we could imagine. In the book, there is Moose, a middle-aged exgifted wise man who has turned into an erratic history professor, still frequently haunted by an epiphany he experienced years ago. Moose is the uncle of little Charlotte; he is also the idol of old Charlotte when he was young. There is a furious Muslim terrorist named $\mathrm{Z}$ who is supposed to bring some disasters to America, he is the former lover of old Charlotte and the lover of little Charlotte. There is a happily married academic who writes the story of old Charlotte and an unhappily divorced private detective who eventually becomes the lover of old Charlotte. There is small Charlotte, a rebellious teenager longing for love who functions as the rescuer of old Charlotte at the end of the story. There is, most strikingly, older Charlotte, the key and linking character in the book, a model from New York who has been in a disastrous car accident. Her face, once her livelihood before the accident, is now a mask she hides behind as she walks past old friends and even ex-lovers, who show no sign of recognition

In Look at Me, Egan "flips back and forth between the worlds of each Charlotte, juxtaposing Rockford and Manhattan, youth and experience, love and empty lust, innocence and jaded experience-yet illuminating the struggles common to each." (Reiter, www.salon.com/books/review/2001/11/14.egan) Focusing on the stories of two Charlottes around their love, longing, disaster, seeking identity and so on, the book reads like both a mystery and a romance fiction, like a detective story and at the same time, a teenage-problem book. Propelled by plot, inspired by different narratives, and displaying an impressive prescience about our newly altered world, the book is more meaningful than it first appears. Ultimately, it takes us beyond what we see and hints at truths we have only just begun to understand.

Egan began the book in the mid-1990s, long before the US succumbed to the Reality TV show and when webcams were almost unheard of. While in the book, Egan puts Charlotte in "The Mirrored Room" where every detail of her life is recorded and webcasted including her memories and dreams. Her recordings and those of other "Ordinary People" offer paying viewers access to an authenticity they lack in their lives. "TV tries to satisfy that, hooks, movies - they try, but they're all so lame-so mediated! They're just not real enough." (LM, 257) The "image" and its culture in the book attract Egan so much that she admits:

In my new novel, Look at Me, I set out to examine the impact of image culture on human identity. How, I wondered has America's emphasis on display — on appearances, literal and metaphorical - altered the makeup of people's private selves? One of the novel's several protagonists works as a fashion model - a job one might call the apotheosis of image culture.

(Egan,http://www.slate.com/articles/arts/culturebox/2001 /09/imaging_the_unimaginable.htm)

It is in Look at Me that Egan, not much for the subtlety, makes the point that she has been getting all along, that is American culture has replaced identity with image. In the book, Egan deftly narrates the model Charlotte's story and at the same time smoothly threads the narrative of Charlotte with those of other characters. As the focus of the book is about the characters' personal belonging in the present society, Look at Me becomes a very charming intellectual 
thriller of identity particularly the relinquishment of identity and of the contemporary image culture.

\section{FOCALIZATIONS IN THE INVISIBLE CIRCUS}

Focalization, probably the most controversial and hotly disputed category in narrative theories, refers to the perspective of a character or the narrator through which the narrated situations and events in a narrative is presented. It also refers to the author's practice of selecting and restricting narrative information and of seeing events and actions from a character's point of view. Focalization strategies are often used to produce artistic effects. In most of the traditional novels and stories, the author adopts a kind of fixed focalization which usually focuses on one single character. Modernist writers, on the contrary, are apt to employ variously innovative strategies of focalization to compose their works and cut their voices from their works and let characters show themselves naturally. Showing instead of telling, therefore, has become a core feature of modern creative writings.

The first person to treat focalization as a writing technique in literary study possibly is Percy Lubbock who makes a systematic study on it in his book The Craft of Fiction. There he puts forward the term "perspective" and defines it as "the relation in which the narrator stands to the story" (Lubboek, 251). In his Narrative Discourse, Gerard Genette points out that most of theoretical works on the subject of perspective confuse the question "who is the character whose point of view orients the narrative perspective" and the question "who is the narrator".

According to Genette, there are three kinds of focalization: zero focalization, internal focalization and external focalization. Firstly, zero focalization, which is equal to the well-known traditional omniscient narrator, means that narrator knows more than the character(s) and he or she may know all about the character(s), including their actions and thoughts. Secondly, internal focalization refers to the kind of focalization in which "the focus coincides with a character, who then becomes the fictive 'subject' of all the perceptions, including those that concern himself as object." (Genette, 1983:74) That is, in internal focalization, the narrator knows as much as the focal character or focalizer. Thus, "the narrative in that case can tell us everything this character perceives and everything he thinks." (Ibid.) Yet, at the same time, the narrator cannot reach the thoughts of other characters except the thoughts of focal character(s). Internal focalization can be divided into fixed focalization, variable focalization and multiple focalizations. To put it briefly, the presentation of narrative events and facts through the constant point of view of a single focalizer is regarded as fixed focalization. Then, variable focalization means different episodes of the story are presented through the eyes of several focal characters, multiple focalization refers to the presentation of a same event repeatedly as seen through the eyes of different focal characters each time. Thirdly, external focalization refers to a kind of focalization in which "the focus is situated at a point in the diegetic universe chose by the narrator, outside every character, which means that all possibility of information about anyone's thoughts is excluded." (Ibid.) Thus, in external focalization, the narrator knows less than the character or that the narrator knows nothing about the thought, mind and psychology of the character. In this kind of focalization, the narrator acts like a camera lens, catching the gestures and actions of character from the outside.

Though Genette classifies different kinds of narrative focalizations, he fails to distinguish first-person external focalization and third-person external focalization. Mieke Bal reformulates Genette and other scholars' focalization by arguing that the terminologies such as "point of view", "narrative perspective" or "narrative point of view" do not make an explicit distinction "between, on the one hand, the version through which the elements are presented and, on the other, the identity of the voice that is verbalizing that vision. To put it more simply: they do not make a distinction between those who see and those who speak.'(Bal, 1985:101) Bal defines focalization as "the relations between the elements presented and the vision through which they are presented." (Bal, 1985:100) That is, focalization is the relation between the vision and that which is "seen" or perceived. Bal also points out that focalization covers both the physical and psychological level of perception. Since the concept of focalization refers to a relationship, so the two poles, both the subject and object of it, should be studied.

In Bal's view, the subject of focalization, the focalizor, is the point from which the elements are viewed. That point can be within or outside a character. If the focalizor is identified with the character, the reader tends to see through the character's eyes and accept the vision presented by the character. Such kind of focalizor is character-bound focalizor and is abbreviated CF. Character-bound focalizor could change and shift from one character to another. A number of characters can also take turns to focalize as a characterbound focalizor. The focalizor that lies with a character taking part in the fabula could be referred to as internal focalizor and labeled IF. Thus, external focalization refers to focalization with an anonymous agent, located outside the fabula, as focalizor. It can also be called non-characterbound focalization. Such an external focalizor or noncharacter-bound focalizor should be labeled EF. Sometimes it happens that the focalization of a $\mathrm{CF}$ is embedded in the vision of the EF and is regarded as the object of the EF. In this kind of situation, the external focalization is on the first level and the character-bound focalization the second level. There are chances that both external focalization and character-bound focalization exist without obvious signs. Thus, there appears double focalization, "in which EF 'looks over the shoulder' of CF." (Bal, 1985:113) The other pole of the relationship of focalization is the focalized object. Focalized object can either be the events or other kinds of elements, such as the scene and characters, etc, which are focalized by a CF or an EF. The focalized object can be either perceptible or non-perceptible. If the focalized object can be perceived both by the focalizor and by other characters in the fabula, it is perceptible. If the focalized object can only be perceived by the focalizor and provides other characters no access to perceiving it, it is called nonperceptible focalized object. (Bal, 1985:115) 
According to Bal, if the focalizor lies with a character who takes part in the fabula, that is, if the focalizor coincides with a character in the fabula, this kind of focalization is called internal focalization. In her first fiction, The Invisible Circus, Egan mainly adopts the internal focalization. As soon as internal focalization strategy is employed, the focalizor and the character in the story coincide with each other, thus the reader would be intended to see through the character's eyes and accept the vision of that character. The vision and perception of that character would be expressed completely because the reader can stand in the character's shoes and feel like experiencing the events or situations of the character. Thus the perception provided by the internal focalizor is more vivid and lifelike than that presented by the omniscient narrator. As for the focalized object, it is also a reflection of the focalizor itself. It implies the aim of the focalizor and reflects the attitude with which the focalizor focalizes. This focalization invites the reader to participate emotionally from the subject-position of the character.

The Invisible Circus is written in the third-person narrative which mainly adopts internal focalization and provides information through the vision of the main character Phoebe. In the book, Phoebe traces the tracks of her hippies elder sister Faith who committed suicide by jumping from a cliff in Italy ten years ago. Phoebe recalls her sister and their father frequently through her running stream of thoughts and feelings. In particular, she always remembers her sister consciously or unconsciously. From the beginning of the fiction, when encountering anyone looks familiar, Phoebe would wonder "if he might have known her sister. She was always wondering that." (IC, 4) When she really meets her sister's old classmate Kyle, she follows the latter to his apartment in order to know more about her sister before committing suicide. There Kyle tries to make love with Phoebe but without success because at that moment, Phoebe loses track of Kyle and reminisces her sister:

But Phoebe had lost track of him. There was something she needed to remember. She shut her eyes, forehead pressed to her knees, and saw Faith and her friends swallow tiny squares of paper and sometime later start laughing, crazy weeping laughter that in Faith soon turned to helpless sobbing in her boyfriend's arms - "Wolf" he was called for his brown skin and white teeth, brown hands on her sister's head...

Now Phoebe looked at Kyle, miles away on the couch. It was always this way-something she needed to remember pulling her back, like an undertow. A white door sealing her off, reminding Phoebe that her present life was unreal and without significance. What mattered was hidden from sight. (IC, 10-11)

"A white door" here may refer to the door or image which connects Phoebe and her sister Faith. Phoebe is haunted by the memory of Faith and overshadowed by her sister's wild adventures. Phoebe is always trying to be more daring, but never succeeding in doing so. She could not find her place and her own identity. Young and secure, what she wishes is that she could become her sister and could belong to the part of her sister's generation, the Sixties. Yet at the same time, she is eager to find her own identity because "she hated remembering, wanted nothing in the world but to rush forward into something of her own, lose herself in it. But this wasn't possible. The only way forward was through that door."(IC, 11) Phoebe is in such a state of dilemma that not only herself but also the reader can view her complicated and confused feelings. The reader observes Phoebe's struggle in searching for her own identity as well as following the track of her sister. Occasionally the reader has a glimpse of the image of the Sixties along with Phoebe. Viewing the surroundings of her working place, Phoebe reflects the image of the Sixties:

Much remained of the sixties: whole-food stores with their bins of knobby fruit, head shops, an occult store full of shrunken heads and tinted crystal balls. But Milk and Honey, where Phoebe worked, had nothing in common with these places. It was a new cafe full of red neon hearts and white tile, owned and run by gay men. Being neither gay nor male, Phoebe of course was on the outside, but the feeling of this was easier, somehow, than being on the outside where she should have belonged. She listened with passionate interest to her colleagues' tales of growing up in strait-laced American towns where they'd dated cheerleaders and made faggot jokes, bluffing their way through one life while they dreamed of another. And here it was. They'd found that promised life and nothing could take it away from them now, or so it seemed. (IC, 63)

Fascinated by the memory of the Sixties, Phoebe views her present life "nothing but the aftermath of something vanished, at which point its details would simply shrink. Her life shrank even when she fought to hold it still." (IC, 67) Therefore she decides to search the aftermath of the vanished Sixties and take departure to her traveling around Europe. Before she leaves her house, the internal focalization shows the complicated feeling of Phoebe: "it came to Phoebe that she wasn't leaving after all, she were merely sinking deeper within this house, entering its hidden world. As if, after years of nudging and prying and tapping, a wall had at lat swung wide and she were stepping through." (IC, 100) Here we can see how confused and contradictory Phoebe is: on the one hand, she is so eager to leave her family to follow the track of her sister's; on the other hand, she is so timid that she dares not take any departure.

Guided by the precious postcards she has preserved for ten years sent by Faith, Phoebe leaves home and starts her journey from London, Amsterdam, France, to Germany, where she meets Faith's lover, Wolf, rather coincidently. Wolf decides to accompany her to Italy, and they have a passionate and feverish affair as they travel to the place of Faith's death. Still through the internal focalization of the third-person narrative, Phoebe, as well as the reader, learns the truth about Faith, the sister whom she has always idealized: Faith was propelled in her action by media representation of the European activists and killed an innocent man by bombing a building. Finally Faith chose to kill herself to escape from the illusioned Sixties. Till then, the vision of her sister and the Sixties smashes abruptly and completely in Phoebe's mind and she seems to begin to feel 
her own existence instead of living in the shadow of her sister:

And she was riven, then by a vision of her sister unlike any she's had before: a girl like herself, reaching desperately for something she couldn't see but sensed was there, a thing that always seemed to evade her. Reaching violently, giving herself to that violence, only to find, when normal life resumed, that she'd done a thing she couldn't live with. (IC, 317)

Step by step, Phoebe has a clear view of her sister as well as herself, and she knows how to live her own life. At that moment, the focalizor coincides with that of the character in the story. Here, Egan ultilizes the internal focalization to bring the reader in the story, she invites the reader to emotionally feel and experience Phoebe's story, faith, confusion, struggle, as well as hope: "In the end you had to. What else was there to do? You left and went on with your life...Phoebe wondered if Faith could have known this when she threw herself away...Time never stopped, it only seemed to." (IC, 319) Eventually, Phoebe succeeds in getting rid of the haunting of her sister and the image of the Sixties. She starts a new life, a life of self-confidence and a life of her own time, a life which fulfills with identity:

Something was gone. But something also was beginning. Phoebe felt this more than understood it - a jittery pulse that seemed to flutter beneath the city. A new decade was upon them. In Barry's office the mood of manic anticipation infected Phoebe at times with a wild certainty that the world was in the grip of transformation. Everyone seemed to feel it - the clean, inarguable power of machines, the promise of extraordinary wealth. It filled them with hope. Phoebe was amazed that the world could ever feel this way again, much less so soon. Yet she felt it herself.

She'd been accepted to Berkeley for January, that was part of it. But something in Phoebe had also relaxed, and now the loose, random way in which her life unfolded seemed to offend her imagination less and less. She still ached to transcend it, cross the invisible boundary to that other the invisible place, the real place. (IC, 337-338)

Egan tactically chooses the focalizor and the focalized object in this fiction to express the feelings and emotional states of her characters. Of course, there may be not exact internal focalization, a story can only use internal focalization as much as possible and usually use it together with an omniscient narrator. "Any single formula of focalization does not...always bear on an entire work, but rather on a definite narrative section. ... External focalization with respect to one character could sometimes just as well be defined as internal focalization through another." (Genette, 1980: 191) But the vision presented by the internal focalizor impresses the reader.

By using mainly the third-person internal focalization, Egan tactically reveals the character's inner feelings and achieves the artistic goal of detached narrative. The narrator is an omniscient narrator who views things from a distance, and narrates events with serene detachment that somehow combines neutrality with sympathy. The narrative strategy of internal focalization in The Invisible Circus also provides us with a vivid picture of the image and leftovers of the Sixties generation which attracts and haunts their next generation.

\section{Alternative NARRATIVE IN LOOK AT ME}

Most narrators present their stories from one of the following perspectives: first-person narrative, or third-person limited or omniscient narrative. Normally, a first-person narrator brings much more focus on the feelings, opinions, and perceptions of a particular character in a story, and on how the character views the world and other characters. If the writer's intention is to get inside the world of a character, then it is a good choice, although a third-person limited narrator is an alternative that does not require the writer to reveal all that a first-person character would know. In a firstperson narrative, the story is usually told by a narrator who is also a character within the story, so that the narrator reveals the plot by referring to this viewpoint character as "I" or, when plural, "we". Often, the first-person narrative is used as a way to convey deeply internal feelings directly, or unspoken thoughts of the narrator. Frequently, the narrator's story revolves around the protagonist and allows this protagonist/narrator's inner thoughts to be conveyed openly to the audience. It also allows this character to be developed further through its own style in telling the story. First-person narrative may be told like third-person one, in the guise of a person experiencing the events in the story without being aware of conveying that experience to an audience; alternatively, the narrator may tell the story to a given audience consciously, perhaps at a given place and time, for a given reason. In extreme cases, the first-person narrative may be told as a story within a story, wherein the narrator is also a character in the story. The first-person narrator can also be the focal character.

For stories in which views of many characters and the context are important, a third-person narrator is a better choice. A third-person omniscient narrator gives a panoramic view of the story, penetrating into many characters and into the broader background of a story. A third-person omniscient narrator can be an animal or an object, or it can be a more abstract instance that does not refer to itself. However, a third-person narrator does not always need to be an omnipresent guide, but instead may merely be the protagonist referring to himself/herself in the third person, also known as third-person limited narrator. Such kind of narrative provides the greatest flexibility to the author, therefore, it is the most commonly used narrative mode in literature. In the third-person narrative mode, every character is referred to by the narrator as "he", "she", "it", or "they", but never as "I" or "we" (first person), or "you" (second person). It is obvious that the narrator in such narrative is merely an unspecified entity or unnamed and uninvolved person that conveys the story, that narrator is not a character of any kind within the story being told. Third-person singular (he/she) is certainly the most common type of third-person narrative, but there have been numerously successful uses of the third-person plural (they). Even more common, however, is to see singular and plural used together in one story, at 
different times, depending upon the number of people being referred to at a given moment in the plot.

While the general rule for novel writing is to adopt a single approach of point of view throughout the novel's entirety, it is not mandatory to conform to this rule. Many stories, especially in literature, shift between the first and third-person narrative can be occasionally applied. In this case, the author moves back and forth between a more omniscient third-person narrator to a more personal firstperson narrator. Epistolary novels, which were common in the $18^{\text {th }}$ century, generally consist of a series of letters written by different characters, and necessarily switching when the writer changes. The classic books such as Frankenstein by Mary Shelley, Dracula by Bram Stoker and The Strange Case of Dr. Jekyll and Mr. Hyde by Robert Louis Stevenson also take this approach.

In her works, Egan shows her capable usage of alternative narrative. Her second fiction Look at Me, her later books The Keep and Goon Squad all adopt alternative narrative between different narrators. Look at Me has two main plot strands, which emerge together in the opening chapter, separate thereafter, and reunite at the fiction's conclusion chapter. Both plot lines center mainly on a character named Charlotte Swenson, and the fiction's twenty chapters alternate roughly between the story of Charlotte Swenson and her namesake Charlotte Hauser. The chapters also alternate between a first-person narrative and a thirdperson narrative. Among the twenty chapters in the book, Chapters one, two, four, seven, eight, ten, twelve, thirteen, sixteen, nineteen and twenty are mainly told from the firstperson narrator "I" by a thirty-five-year-old fashion model Charlotte Swenson who tells her own story. The other chapters of the fiction are narrated from an omniscient thirdperson narrative which mainly focus on a teenager girl named Charlotte Hauser, whose life in Rockford centers around two older men, Michael West/Z, little Charlotte's lover who disguised as a math teacher but actually a terrorist from the Middle East, and Moose Metcalf, little Charlotte's weird and nostalgic uncle.

The first part of Look at Me, "Double Life", is dominated by the first-person narrative telling the story of the older Charlotte, Charlotte Swenson. Callous, impulsive and selfish, Charlotte Swenson tries to claw her way back to the glossy Manhattan fashion circle, but she finds that her new face is no longer qualified after a car accident which disfigured her more or less. The opening sentence is Charlotte's own statement on how she is viewed by others after the car incident which happened on the way to her despised hometown Rockford, Illinois: "After the accident, I became less visible. I don't mean in the obvious sense that I went to fewer parties and retreated from general view. Or not just that. I mean that after the accident, I become more difficult to see." (LM, 3) The first-person narrative immediately draws the reader's attention and brings him/her much closer to the narrator to learn more about her story. Subsequently, Charlotte tells us her life and work after the accident. Surrounded by refracted image of herself, Charlotte returns to New York and finds that her former identity has been lost and relinquished. After the accident, nothing can be done successfully and completely, including her job, her life, her love and even her sex. Without her old image, she must begin to search for a new identity. In essence, Charlotte is dismissed as an entity, but she never gives up her way of seeking her new image. Jane Smiley admires this quality and states: "Charlotte is required to move forward, resolving her employment situation and her identity crisis, and to work backward, figuring out her accident, simultaneously." (Smiley, 569) Though Smiley admits that Charlotte is not a sympathetic character, "aggressive, resentful, and shallow", she still approves that Charlotte is "brave, which keeps the reader reading."(Ibid.)

Along the way of relinquishing her former image as well as seeking her new image, Charlotte Swenson, in the form of first-person narrative, shows us the ability that she can glimpse people's "shadow selves", that is, the true characteristics behind their public personas, "that caricature that clings to each of us, revealing itself in odd moments when we laugh or fall still, staring brazenly from certain bad photographs."'(LM, 43) After her car accident, she has a business date with Oscar, her former booker. At that moment Charlotte reveals the "shadow self" of Oscar:

Oscar's was a portrait of sheer grief, a lace so anguished it resembled a death's head. Not that Oscar himself looked anything like this; he had a lively, beautiful face and perfect white teeth (not a single cavity, he'd told me). It was only occasionally, when he dragged on a cigarette, that I glimpsed the other-a nagging, flickering presence. I had been studying people's shadow selves for many years, but Oscar's still had the power to shock me-so gaping was its contrast to his apparent self. Yet this was often the case in the fashion world, where beauty, the best disguise of all, was so commonplace. (LM, 43-44)

Recommended and arranged by Oscar, Charlotte has an appointment with a photographer who is ready to take photos for the models by cutting their faces into blooding. At that moment Charlotte also deploys her unique ability to observe the "shadow self" of this cruel butcher-like photographer:

Gently, Ellis lifted the blade to the girl's brown cheek, then dipped one corner under her skin like a swimmer testing the water with a toe. The girl flinched, but didn't make a sound. With delicacy and swiftness, Ellis pulled the blade through her skin. His shadow self appeared without my even looking for it: the gentle butcher, who massages his victims to loosen their flesh before putting in the knife. Blood dropped from the wound, and at the same time, tears rose in the girl's eyes and spilled from the corners. (LM, 187)

In the second part of the fiction, "The Mirrored Room", the model Charlotte is approached by an Internet entrepreneur Thomas Keene whose scheme is to provide life stories over the Internet in what appears to be a cross between blogging and novel-writing. Charlotte, who was once famous, will be paid a high price for the simultaneous drama and celebrity of her story, which will be written up with pictures and posted on the Web. After quite a period of struggle and her attempt to recapture her former identity as a fashion model without success, Charlotte decides to search for her present identity by selling her story to the Internet 
entrepreneur and showing her private life to the public. By exposing her real image to others, the "I" narrator of the model Charlotte declares that she is free from her old image and starts a journey of relinquishing her image as well as her identity:

So here it was: exposure. The very thing I had craved since childhood, perhaps the only thing I had never tired of or ceased to love or changed my mind about-now offered to me inexplicably, unexpectedly, over lunch. A chance to tell who broke me and how. Blab to the world and get paid. Court the audience I had always desired.

The mirrored room had opened its doors to me finally, after so long! But it was too late, I was too tired. Too accustomed to my exile.

I'm free, I thought, swinging my arms. And I felt the possibility of a different kind of life, a life in which I wanted different things. (LM, 264-265)

After selling her image and story to the Internet entrepreneur, the old Charlotte becomes famous again, she (actually her story) is known by more people, "I had begun to feel, as I went through the motions of my life, that I was someone other than that woman, Charlotte Swenson, in whose skin I had lived for so long."(524) Charlotte, the model, who progresses from a state of disappointment and frustration to a state of accepting what has happened around her by the end, successfully sells her story and finds her new identity and moves out of the "mirrored room":

I sold Charlotte Swenson for a sum that will keep myself and two or three others comfortable for the remainder of our lives, although not (I'm told) for nearly what she was worth.

As for myself, I'd rather not say very much. When I breathe, the air feels good in my chest. And when I think of the mirrored room, as of course I still do, I understand now that it's empty, filled with chimeras like Charlotte Swenson - the hard, beautiful seashells left behind long after the living creatures within have struggled free and swum away. Or died. Life can't be sustained under the pressure of so many eyes. Even as we try to reveal the mystery of ourselves, to catch it unawares, expose its pulse and flinch and peristalsis, the truth has slipped away, burrowed further inside a dark, coiled privacy that replenishes itself like blood. It cannot be seen, much as one might wish to show it. It dies the instant it is touched by light. (LM, 525)

With this direct first-person narrative, Egan invites the reader to participate in the story, to bring the reader close to Charlotte and even in the same situation with Charlotte, to feel the rising and falling of her work and life, to experience her sorrow, her struggle, her desperation as well as her later redemption. What's more, through the first-person narrative, not only the old Charlotte, but also the reader has a further understanding of the pervasive and all-diffused pseudoimage in American society, particularly in the model world.

Contrary to the first person "I" narrating the story of the model Charlotte, Egan alternates with the third-person narrative when dealing with the stories of little Charlotte, Charlotte Hauser, the daughter of model Charlotte's childhood friend, and various people around her, including her uncle Moose Metcalf and her elder lover Michael West. The third-person narrative concerns how the little Charlotte searches for her identity and how she deals with the relations with the two men from a third person's view. On the one hand, because she is ordinary looking, self-abased and neglected in her family, little Charlotte tries to seek her identity by having sexual relations with her middle aged math teacher Michael West, also Z, a terrorist who comes from the Middle East and who is most possibly the chief culprit of model Charlotte's car accident. On the other hand, little Charlotte follows her uncle Moose to studying the history of Rockford to fulfill her uncle's unfinished dream.

Besides little Charlotte, the other characters are also narrated from third-person narrative. Little Charlotte's uncle Moose Metcalf, once an attractive energetic young man, now turns into an erratic history professor. He is a person who most embodies the feeling of anti-postmodernism in Look at $M e$. Moose was put into jail because he fired a gun when he was teaching in the class. After that he has turned into a quiet and weird person. What he hopes is that his niece Little Charlotte would follow him to fulfilling his ambitions of composing a multivolumed book about the history of his hometown whose explicit purpose is "to discover what had gone wrong between its founding in 1834 and the present day-what, precisely, had been lost in the ineluctable transformation from industry to information." (LM, 73) Therefore, he patiently guides her and teaches her how to finish the work. Unfortunately, his niece little Charlotte finally rebels against him and gives up the idea of following him. When his niece told him that she would not study with him anymore, he was so disappointed and depressed that he drove wildly in the stormy wind and bellowed: "It's the end of the world!'(LM, 509)

Just as the case that model Charlotte is so eager to go back to the past without success, Moose's story in the fiction symbolizes a feeling of nostalgia for the world before the industrialization and a feeling of disgust and hatred toward industrialization. The process of modernization, according to him, is a way of devastating human civilization and creating the phony post-modern ideas, discourses and images. One of his major academic projects, for instance, on the history of Rockford, comes to him in a moment of vision which is quite similar to that of the model Charlotte:

Moose looked across the river and felt the past unroll suddenly from behind the present panorama of dead chrome and glass and riverfront homes as if a phony backdrop had toppled, exposing a labyrinth. "It's all here," he murmured wonderingly, and experienced a lifting within himself. "Everything is here". (LM, 72)

Just as the model Charlotte who has also witnessed the connection of postindustrial to industrial New York in the ghostly old signs, Moose sees the history of Rockford unrolling in the trend of postmodernism. It leads him to embark on the history of his hometown with the help of his niece.

By tactically shifting narrators between first person and third person, Egan smoothly flips back and forth between the 
worlds of the old model Charlotte and little Charlotte and people around them. Through the first-person narrative, Egan not only brings the reader closer to the model Charlotte and explores more about her later life, but also uncovers the seemingly mystery but really flashy and narcissistic side of the her life. Through the third-person narrative, Egan provides vivid pictures of as well as her attitudes towards the characters such as little Charlotte, a rebellious teenage girl who is eager to find her identity through some mischievous way, and her uncle Moose, a sufferer of the modern society, and the other characters in the fiction. According to the contemporary philosopher Seyla Benhabib's:

When the story of a life can only be told from the perspective of the others, then the self is a victim and sufferer who has lost control over her existence. When the story of a life can only be told from the standpoint of the individual, then such a self is a narcissist and a loner who may have attained autonomy without solidarity. (Benhabib, 198)

That is, the old Charlotte, once a successful and arrogant fashion model, employs the first person narrative because she believes that she has the power to control her life and tell her own story, though what she has hoped eventually proves to be deceived phony image. On the opposite, little Charlotte, who always has no confidence in herself particularly in her own image, is not endowed with the ability to handle her own life. Therefore, her story must be narrated from a thirdperson narrator. Interestingly as well as coincidentally, the two Charlottes met at the opening of the story, then they went on living in different life trails and have never met again till almost at the very end of the story. When the old Charlotte returns to her hometown shooting a film based on her car accident, the little Charlotte arrives as the savior of her in an amazingly incidental way. At that point, the two Charlottes recognize each other and seem to find their own identities and real images from the other side of themselves.

\section{UNRELIABLE FIRST-PERSON NARRATIVE IN LOOK AT $M E$}

Unreliable narrative refers to a literary device in which the credibility of the narrator is seriously undermined and doubtable. The concept of unreliable narrator is acknowledgedly brought up by Wayne Booth in The Rhetoric of Fiction, in which he differs unreliable narrator from reliable narrator by stating "I have called a narrator reliable when he speaks for or acts in accordance with the norms of the work (which is to say the implied author's norms), unreliable when he does not" (Booth, 1983: 158159). Booth provides two axes to see whether a narrator is reliable or not: one is the axis of facts/events, the other the axis of values/judgments which focus on ethics. According to Booth, this unreliability of a narrator is probably due to his/her psychological instability, a powerful bias, a lack of knowledge, or even a deliberate attempt to deceive the reader or the audience.

Booth's "unreliable narration" has been adopted and improved by the American narratologist James Phelan who also relies much upon the axis of ethics and evaluation to develop the concept of unreliable narrator. At the same time, Phelan adds another axis of knowledge/perception and further classifies unreliability into different types, such as misregarding and underregarding. From the joint effort of Booth and Phelan, the three criterions of unreliability have come into effect for the reader to judge and illustrate the unreliable narrator. As for the first category: violating the axis of facts/events, an unreliable narrator is either underreporting (that is, to report the facts inadequately) or misreporting (that is, to give the incorrect information about the events). As for the axis of values/judgments, a narrator can be unreliable for its underregarding through its limited perspective or misevaluating things due to misinterpreting the motives or actions of characters. Finally, for the axis of knowledge/perception, a narrator would fail to see the connections between events; he/she would be misled because of being trapped in mental disorder. The three axes of unreliable narrator play an important role in determining whether a narrator is speaking for or acting in accordance with the implied author. Moreover, an unreliable narrator can be unreliable by deviating from one of the axes, or more than one at the same time in any individual text.

In Look at Me, Egan utilizes first-person retrospective narrative to narrate the fashion model Charlotte's story after the car accident. In the first part of the book, "In my memory", model Charlotte tells us her memory of the accident in the second paragraph:

In my memory, the accident has acquired a harsh, dazzling beauty: white sunlight, a slow loop through space like being on the Tilt-A-Whirl (always a favorite of mine), feeling my body move faster than, and counter to, the vehicle containing it. Then a bright, splintering crack as I burst through the windshield into the open air, bloody and frightened and uncomprehending. (LM, 3)

This aesthetic description of a physically brutal event compares Charlotte's memory as a series of clashing images: "dazzling beauty," "white sunlight," "splintering crack," "bloody and frightened", the mix of horror and beauty, fear and desire, which not only symbolizes the perfect aesthetic of modern cultural engagements with the automobile but also shows that Charlotte has such a clear memory of the car accident that her description is so convincing. The fiction's third paragraph, however, reveals that Charlotte's retrospective narrative is artificial and unreliable:

The truth is that I don't remember anything. The accident happened at night during an August downpour on a deserted stretch of highway through corn and soybean fields, a few miles outside Rockford, Illinois, my hometown. I hit the brakes and my face collided with the windshield, knocking me out instantly. ... The shatterproof windshield did indeed hold fast upon its impact with my head, so although I broke virtually every bone in my face, I have almost no visible scars. (LM, 3)

It now appears that Charlotte's memories in the two paragraphs are quite different. The account in the third paragraph is less heightened and more denotative, seems more associated with "the truth" and the truth is that Charlotte seems to have no memory of the car accident or 
she is unwilling to recall the accident, because in unreliable narrative, "the narrator is mistaken, or he pretends to have qualities which the implied author denies him."(Booth, 1983:159) This unreliable narrative surely leaves the reader the mystery and at the same time stimulates the reader to explore more about the truth.

Apart from the unreliable narrative on the car accident, Charlotte also reveals to the reader that she has the ability to observe the "shadow selves" of other people as well as some images. Early in the fiction, in response to a wry joke by her fashion agent Oscar while they were walking out onto the New York streets after meeting for the first time since her surgery, Charlotte remarks that she sees some images:

I said, and laughed, my head back, so that suddenly I was looking above the buildings, up at the winter sky. And then I saw the sign. It snagged my gaze and held it, an old advertisement painted on the side of a brick building. Griffin's Shears, it read. The paint was faded but still legible, a faint chalky blue, and beside the words I made out the silhouette of a pair of scissors ...

Oscar looked up and down, then swiveled his head. "What?"

"That old ad! Griffin's Shears."

Oscar looked at me.

“It's like a ghost," I said.

We stood there, looking at the ad. I felt moved by it in some way I couldn't explain. It reminded me of Rockford, of its factories and smokestacks and industry. A glimpse of New York's shadow face. (LM, 48-49)

Because of the unreliable first-person narrative, it remains unclear in the quoted passage whether Charlotte is really seeing the image of Griffin's Shears on a New York wall, or more accurately, whether the image really exists to be seen. It is also uncertain whether Oscar sees the sign: he looks up and down, and then at Charlotte, but he does not answer. His silence does not confirm the notion whether he shares her vision. This unreliable narrative appears a little later again, when Charlotte sees another sign of "Hollander Ladies Underwear":

It's a sign, I thought, the wind gulping my laughter. A sign in the form of a sign.

At the corner of Sixth Avenue and Twenty-eighth Street I stopped and turned slowly around. They were everywheresigns and the possibility of signs, many faded to translucence, as if I'd gained some new power that allowed me, finally, to see them. "Harris Suspenders Garters Belts." "Maid-Rite Dress Co."; mementos of the gritty industrialism I'd come to New York to escape. But today the signs looked honest, legible in a way that the negligéed models I'd seen this morning in Vogue, prone in a parking lot surrounded by broken glass, would never be. (LM, 91)

The change in the quoted passage is more firmly located in Charlotte's own subjectivity, that is, her unreliable narrative: "as if I'd gained some new power that allowed me, finally, to see them."(LM, 91) Charlotte feels empowered by interpreting her vision as "a sign in the form of a sign", thereby turning that vision into something other than a postmodern joke.

By means of unreliable first-person narrative, Egan shows that Charlotte Swenson, as an unreliable narrator, is so unwilling and deceptive that she pretends not to remember the facts of the car accident in which she has lost her beautiful appearance. Charlotte has to face up with the cruel reality by relinquishing her proud image as well as accepting a phony one in "a mirrored room". The unreliable firstperson narrative also reflects Egan's deep concerns about the image culture. Charlotte has the ability to see "signs and the possibility of signs," and to connect them to historical referents to see the world as characterized less by the loss of history than by its suppression. The ambiguous existence of these images symbolizes that "it remains significantly uncertain whether reality in these scenes exists primarily on the side of the subject or on the side of the object, the historical mark on the wall.'(Kelly, 415)

\section{CONCLUSION}

Deploying internal focalization to narrate the stories about Phoebe and her hippie sister Faith, Egan's first fiction The Invisible Circus brings Egan admiring critical admiration for its portrayal of the Sixties counterculture and the image represented by that generation. In this book, Egan takes up the burden of history and shows clearly how those turbulent 1960s and 1970s shaped the lives of her generation. One of the most important points in the book is how the Sixties counterculture movement influences Faith and her generation and how Faith was propelled in her action by media representation by the 1960 s. Perhaps one of the most charming motifs in the fiction is the mention of the wellknown Patty Hearst and her story and how it impacted Faith. Influenced by Hearst and the celebrity image of Hearst generation, Faith in The Invisible Circus gets caught up by the Red Army Faction Baader-Meinhof gang in Germany. Her radical activity reaches the culmination in the death of an innocent man, an act that haunts her so much and eventually leads to her final suicide. While it is successful in exploring the feeling that most people brought up in the 1970s who were influenced by the 1960s generation, it is even better at portraying the excitement, danger, loneliness, and naivety that are important parts of a girl's first trip to Europe. This fiction leads us to ponder the elusiveness of memory and the ephemeral nature of experience. Faith's search for "real life" and the tragic consequences of her search prompts the reader to reflect on the nature of the ordinary versus the unusual, the struggle for balance between routine and risk.

Egan's second fiction Look at Me is about "bigger things": double lives, secret selves, the difficulty of really seeing anything in a world so flooded with image. It deals with the issues on image culture not in a "trendy" way but in depth and with conviction. It is a book "impressive prescience about our newly altered world."(Reiter, www.salon.com/books/review/2001/11/14/egan) In particular, Look at $\mathrm{Me}$ is more meaningful that it first 
appears. It takes us beyond what we see and symbolizes the truths we have only just begun to understand. "Few recent books have so eloquently demonstrated how often fiction, in its visionary form, speaks of truth." (Miller, www.salon.com/books/int/ 2001/11/14/egan) The "truths" revealed by Look at Me may refer to that modern media encourages us to assume the virtual as real, the image for the reality and the virtual images shape and distort out notions of what we are experiencing.

Egan's books are idea-driven and she readily admits her concerns and exploration on the issues about image culture. "For me a story is not interesting if there isn't a philosophical query along with it." (Miller, www.salon.com/books/int/ 2001/11/14/egan) Both fictions in her early writing period are about the image culture, including the influences that the images of the Sixties counterculture upon people after that, the ultimate embodiment of society's obsession with look and fame, the shifting from the industrial age to the information age, and in the way resistance to social mores and the manufactured world can engender rage and even violence.

\section{REFERENCES}

[1] Bal, Mieke. 1985. Narratology: Introduction to the Theory of Narrative [M]. Toronto: University of Toronto Press.

[2] Benhabib, Seyla. 1992. Situating the Self: Gender Community and Postmodernism in Contemporary Ethics [M]. London: Routledge.

[3] Booth, Wayne C. 1983. The Rhetoric of Fiction [M]. 2nd ed. Chicago and London: University of Chicago Press.

[4] Egan, Jennifer. 1995. The Invisible Circus [M]. New York: Anchor Books.

[5] Egan, Jennifer. 2001. Look at Me [M]. New York: Anchor Books.

[6] Genette, Gerard. 1983. Narrative Discourse Revisited [M]. New York: Cornell University Press.

[7] Kelly, Adam. Fall (2011), 391-422. "Beginning with Postmodernism" [J]. Twentieth-Century Literature.

[8] Miller, Laura. Nov. 15(2001). "Face Value — Look at Me by Jennifer Egan" [OL]. Salon. http://www.salon.com/2001/11/4/egan

[9] Phelan, James. 2005. Living to Tell about It [M]. Ithaca: Cornell University Press.

[10] Reiter, Amy. Nov.14(2001). "Look at Me by Jennifer Egan” [OL].Salon.www.salon.com/books/review/2001/11/14/egan.

[11] Smiley, Jane. 2006. Thirteen Ways of Looking at the Novel[M]. New York: Alfred A. Knop. 